\title{
Lessons on Change: Shifting to Online Learning During COVID-19
}

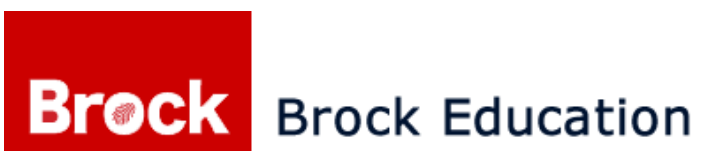

A journal of educational research and practice 2020 Vol. 29 (2) 47-51

https://journals.library.brocku.ca/brocked

\section{Ruth McQuirter* \\ Brock University}

\begin{abstract}
The current COVID-19 pandemic has presented educators at all levels of schooling with the challenge of converting face-to-face instruction to online learning. Past efforts to enact educational change, especially the adoption of technology in the classroom, have had mixed results. The author outlines frequent barriers to successful pedagogical change and contrasts these with observations of positive change strategies employed by her institution in moving to online learning. The essay concludes that strong institutional support for the development of technical skills, coupled with collegial sharing and building on current practices, leads to a sense of agency among instructors and a greater willingness to embrace change.

Keywords: educational change, online learning, technology in education, communities of practice

*rmcquirter@brocku.ca
\end{abstract}


After more than 40 years as an educator in varied roles-classroom teacher, department head, curriculum consultant, and professor in a faculty of education-I have lost count of the innovations proposed for education. Some have focused on content to be covered, some on pedagogical strategies employed in classrooms, others on the hardware and software used to deliver programs. A common denominator has been the frequency of ineffective implementation of curriculum change.

This essay is a brief reflection on common impediments to successful transitions in education in contrast to my recent positive experiences of educational change during the COVID-19 pandemic. I explore the factors that have made the mandated shift to online learning in teacher education for the upcoming fall term dramatically different than most initiatives that promote change. Although the current educational climate may be unique, the principles I suggest have relevance to curriculum innovations going forward. I would hope that those involved at various levels of curriculum change, including the Ministry of Education, school board, and higher education personnel along with school-based support networks follow the basic advice of the paper: that strong institutional support be provided to teachers, collegial sharing be fostered for teachers implementing the changes, and change be scaffolded by building on positive aspects of current practice.

\section{Barriers to Educational Change}

Teachers, as classroom frontline workers, often learn to approach new ideas in education with scepticism (Jenkins, 2020; Johnson \& Batchelor, 2018). Many so-called breakthroughs have been advocated by theorists with little actual classroom experience and minimal research to support their claims (McGrath et al., 2016). Too little support is given for developing the knowledge and skills needed to apply new strategies in a real-world classroom context (Siegel et al., 2017). Teachers are often deprived of a sense of agency, defined by Priestley (2011) as "the capacity of individuals to act reflexively within the possibilities bounded by their social and material environments to effect changes to their conditions or to reproduce them" (p. 16). As a result, educational change has often been slow, inconsistent, and resisted by many practitioners (Durff \& Carter, 2019).

Technology in education is certainly an area of change that has been problematic. The unexpected arrival of COVID-19 and the almost overnight need to move delivery of programs online at every level of schooling has exacerbated an already uneven implementation of digital technology. Today's teachers are faced with a myriad of platforms and ever-changing digital tools in their delivery of new content. Not unexpectedly, the embracing of technology has been fragmented at best (OECD, 2011). 
These demands multiplied over the past year when teachers had to move from a face-to-face model to a fully online platform in the absence of prior training, modelling of best practices, or easily accessed technical support. Fullan et al. (2020) provide a three-stage model to describe how schools are adapting to online learning, beginning with Disruption, moving to Transition, and finally to Reimagining. Many teachers are still in the Disruption stage, dealing with the technical aspects of delivery, unable to ask larger questions related to the cognitive, social, and emotional needs of children in an online environment.

\section{Fostering Agency}

Instructors in my higher education institution also faced the challenge of switching to online learning mid-semester, with all courses moving online this fall. Few instructors in our Teacher Education program have taught online courses in the past, although all are familiar with using a Learning Management System (LMS) in their face-to-face classes. Rather than detecting any resistance, however, I have been amazed by the positive reaction from all levels of the institution to the possibilities of this shift, especially when most instructors could simply take their existing PowerPoint slides and post them to the LMS. The temptation to do so is understandable considering we anticipate fully online courses for just one term. Such openness to innovation in technology has not always characterized our faculty, with uneven implementation similar to that of teachers in schools. As both a participant and an observer, I have pondered what makes this experience in the midst of a pandemic different. The answers I propose could represent an antidote to many of the blocks to educational change I have witnessed throughout my career.

\section{Institutional Support}

Whereas teachers in elementary and secondary schools were offered little if any systematic training in full online delivery, my colleagues and I have been surrounded by support. Even before the official decision was made to move the fall offerings online, instructors were offered many chances to engage in professional development (Hunt, 2020). The university has introduced Microsoft Teams as one of two platforms for videoconferencing. Since Teams is new to most faculty, there were numerous synchronous workshops provided by trusted technology staff, a Help Desk for individual support, and tutorials. We were encouraged to reach out individually if we had further questions. Time was dedicated in department meetings for sharing concerns and experiences, and faculty who were now teaching online readily described their successes and challenges. In essence, we became a Learning Community.

\section{Collegial Sharing}

Many elementary and secondary teachers describe a feeling of isolation as they attempt to manage the complex technical, social, and pedagogical challenges presented by synchronous 
and asynchronous instruction. In stark contrast, I have felt more closely connected to my colleagues than I experienced pre-pandemic when working on a satellite campus. In addition to scheduled professional development, I have witnessed and participated in numerous support groups formed by colleagues. Initially these groups met on Teams as a way of becoming familiar with the tool, but as time passed our discussions evolved to deeper questions such as how to engage in authentic assessment practices in online learning, foster meaningful collaboration in our classes, and make real-world connections through the platform. Similar to communities of practice (Wenger-Trayner \& Wenger-Trayner, 2015), we set our own agendas, reach out for institutional support as needed, and ground our discussions in scenarios we anticipate facing in September.

\section{Building on Current Practice}

Too often a new direction in education is presented as a panacea to address inadequacies in current practice. Our move to online learning, however, has not been touted as superior to face-to-face formats. Workshop leaders and our Program Director emphasized from the beginning that technology and the tools available should not drive our decisions. We were challenged to build on core principles from our face-to-face courses, be realistic about the amount of content we could cover online, and then choose tools that support these goals. The student experience is central to our decisions. As a result, we have generated ideas about using technology tools that we hope to incorporate in future classes when we return to face-to-face or blended instruction.

\section{Conclusion}

The cumulative effect of strong institutional support for the technical aspects of delivering online courses, combined with the spontaneous development of communities of practice, has been to foster agency among faculty. We have been able to build on what we do well while using the challenges of online platforms to re-examine our courses and experiment with innovations that we hope to incorporate in future face-to-face formats. Priestley (2011) suggests that agency is past-oriented, with individuals building on past experience, but projected to the future and rooted in the possibilities of the present (p. 16).

I do not suggest that educational change in higher education can be mapped seamlessly onto elementary and secondary contexts. Nevertheless, I believe that basic principles such as building on the strengths of current practices, encouraging and facilitating teacher collaboration, and providing focused, systematic, multi-level implementation support are building blocks for innovation regardless of grade level or curriculum area. 


\section{References}

Durff, L., \& Carter, M. (2019). Overcoming second-order barriers to technology integration on K-5 schools. Journal of Educational Research and Practice, 9(1), 246-260. https://doi.org/10.5590/JERAP.2019.09.1.18

Fullan, M., Quinn, J., Drummy, M., \& Gardner, M. (2020). Education reimagined: The future of learning -A collaborative position paper between New Pedagogies for Deep Learning and Microsoft Education. http://aka.ms/HybridLearningPaper

Hunt, D. (2020, July 9). Workshops prepare instructors for online learning this fall. The Brock News. https://brocku.ca/brock-news/2020/07/workshops-prepare-instructors-foronline-learning-this-fall/

Jenkins, G. (2020). Teacher agency: The effects of active and passive responses to curriculum change. The Australian Educational Researcher, 47, 167-181. https://doi.org/10.1007/s13384-019-00334-2

Johnson, B. W., \& Batchelor, M. (2018). Collaborative resistance to digitized instruction in a rural middle school. Middle School Journal, 49(3), 4-16. https://doi.org/10.1080/00940771.2018.1439664

McGrath, C., Barman, L., Stenfors-Hayes, T., Roxa, T., Silen, C., \& Bolander Laksoo, K. (2016). The ebb and flow of educational change: Change agents as negotiators of change. Teaching and Learning Inquiry, 4(2), 1-14. https://doi.org/10.20343/teachlearninqu.4.2.9

OECD. (2011). Education at a glance 201 1: OECD indicators. OECD Publishing. http://dx.doi.org/10.1787/eag-2011-en

Priestley, M. (2011). Schools, teachers, and curriculum change: A balancing act? Journal of Educational Change, 12(1), 1-23. https://doi.org/10.1007/s10833-010-9140-z

Siegel, D., Acharya, P., \& Sivo, S. (2017). Extending the technology acceptance model to improve usage and decrease resistance toward a new technology by faculty in higher education. The Journal of Technology Studies, 43(1), 58-69. https:/ / doi.org/10.21061/JOTS.V43I2.A.1

Wenger-Trayner, E., \& Wenger-Trayner, B. (2015). Introduction to communities of practice: $A$ brief overview of the concept and its uses. https://wenger-trayner.com/introduction-tocommunities-of-practice/ 